\title{
A new polyphysacean alga from the Miocene of Romania and its biomineralization
}

Filippo Barattolo, Viorel Ionesi, and Paul Ţibuleac

Acta Palaeontologica Polonica 64 (1), 2019: 85-100 doi:https://doi.org/10.4202/app.00537.2018

Polyphysacean algal fertile caps from the Sarmatian near Suceava (NE Romania) are here described as a new species, Acetabularia moldavica, ascribed to the extant genus Acetabularia due to the presence of both inferior and superior coronae. Gametangia are preserved and closely packed within the gametophore. The gametangium wall is strongly mineralized and SEM observations show acicular aragonite crystals arranged perpendicularly to the wall surface. The occurrence of mineralized cyst walls distinguishes the new species from the other three species ascribed to the genus Acetabularia, namely Acetabularia miocaenica, Acetabularia chiavonica, and Acetabularia transylvana. Cyst wall biomineralization in $A$. moldavica sp. nov., Chalmasia, and Halicoryne appears to assist in distinguishing taxa at species level but not at genus level. Four types of intracellular biomineralization can be recognized in polyphysaceans according to the mineralization of cyst walls and intergametangial spaces. The attribution of an extant species to a fossil genus and vice-versa can be problematic when the fossil consists of a mineralized spicule (intracellular biomineralization). Two contrasting examples are Acetabularia schenckii (extant species) assigned to the genus Acicularia (fossil), and Halicoryne morelleti (fossil species) referred to an extant genus (Halicoryne). When it is unclear whether fossil taxa possessed one or two coronae, the attribution of Cenozoic species to an extant genus appears speculative. Therefore, we support the view that the genus Acicularia should only be applied to fossil species. In addition, mineralized aggregates of cysts of Halicoryne morelleti should be distinguished from their possible extant counterparts (Chalmasia, Halicoryne, and Acetabularia ) when coronal structures are not preserved. In the literature Halicoryne morelleti has been compared with the fossil genera Sedalanella and Ioanella. The first genus must be considered a junior synonym of Oroseina. A new interpretation of the genus Ioanella is supplied. The two layers of cysts of Ioanella conform poorly with the small ellipsoidal calcareous bodies of Halicoryne morelleti. Therefore, we propose the new genus Patruliuspora for Halicoryne morelleti.

Key words: Dasycladales, Polyphysaceae, biomineralization, Miocene, Sarmatian, Romania.

Filippo Barattolo [ilippo.barattolo@unina.it], Dipartimento di Scienze della Terra 
dell'Ambiente e delle Risorse, Università degli Studi di Napoli Federico II, Complesso universitario di Monte Sant'Angelo, via Cintia 21-80126 Napoli, Italy. Viorel Ionesi [vioion@uaic.ro ] and Paul Ţibuleac [paul.tibuleac@uaic.ro], Department of Geology, University Alexandru Ioan Cuza, Bulevardul Carol I, 20 A, 700505 Iaşi, Romania.

This is an open-access article distributed under the terms of the Creative Commons Attribution License (for details please see creativecommons.org), which permits unrestricted use, distribution, and reproduction in any medium, provided the original author and source are credited.

FoF Full text $(1,809.8 \mathrm{kB})$ 